\title{
Research on Road Roughness Based on NARX Neural Network
}

\author{
Yingjie Liu $\mathbb{D}$ and Dawei Cui $\mathbb{D}$ \\ School of Mechanical-Electronic and Vehicle Engineering, Weifang University, Weifang 261061, Shandong, China \\ Correspondence should be addressed to Yingjie Liu; ufoliuyingjie@163.com
}

Received 11 August 2021; Revised 16 November 2021; Accepted 29 November 2021; Published 14 December 2021

Academic Editor: Shangce Gao

Copyright (c) 2021 Yingjie Liu and Dawei Cui. This is an open access article distributed under the Creative Commons Attribution License, which permits unrestricted use, distribution, and reproduction in any medium, provided the original work is properly cited.

\begin{abstract}
In order to solve the problem of road roughness identification, a study on the nonlinear autoregressive with exogenous inputs (NARX) neural network identification method was carried out in the paper. Firstly, a 7-DOF plane model of vehicle vibration system was established to obtain the vertical acceleration and elevation acceleration of the body, which were set as ideal input samples for the neural network. Then, based on the plane model, with common speed, the road roughness was solved as the ideal output sample of the NARX neural network, and the road roughness of B-level and C-level was identified. The results show that the proposed method has ideal identification accuracy and strong antinoise ability. The relative error of C-level road roughness is larger than that of B-level road roughness. The identified road roughness can provide a theoretical basis for analyzing the dynamic response of expressway roads.
\end{abstract}

\section{Introduction}

Road roughness is usually used to describe the degree of undulation of the road surface. It is the main incentive in the driving process of a vehicle and affects various aspects such as riding comfort, handling stability, component fatigue life, transportation efficiency, and fuel consumption. Therefore, it is of great significance for automotive engineering technicians to study and analyze road roughness [1].

Road roughness is an important evaluation indicator of road surface, which not only affects the driving comfort of drivers and passengers but also is related to vehicle vibration, driving speed, tire friction and wear, and vehicle operating costs. When the vehicle is driving, the unevenness of the road surface will arouse vibration of the vehicle. When the vibration reaches a certain level, it will make the passengers feel uncomfortable and fatigued. The roughness of the road, which is the main vibration excitation source of the vehicle, plays a vital role in the research and development of the durability, handling stability, reliability, NVH (noise, vibration, and harshness), and several parts and systems of vehicle [2].

The ride comfort of a vehicle is a comprehensive reflection of the vehicle body's excitation on the road surface. The vibration caused by the excitation of the uneven road surface not only affects the driving smoothness and safety of the vehicle but also affects the fatigue life of the vehicle parts [3].

In the analysis of vehicle ride comfort and handling stability, whether the road roughness can accurately reflect the actual road surface has a fundamental impact on the accuracy of the analysis.

Therefore, the determination of a reasonable road roughness is one of the problems to be solved in the research of vehicle ride comfort and handling stability. However, the early road roughness was obtained by measuring and recording the unevenness of the road surface by a special road measurement and data processing as well as calculation. Because the road measurement is expensive, it is difficult for some inspection departments to equip it. With the development of computer technology and other related disciplines, people have begun to model road surfaces and simulate them in order to analyze and predict vehicle ride comfort. At present, scholars from various countries have conducted a lot of research on the digital simulation of road roughness, including pseudowhite noise method and harmonic superposition algorithm. However, the simulation accuracy of these methods is not very high. The paper applies load identification technology to identify road roughness $[4,5]$. 
The road roughness identification problem has been studied in the literature. A brief review is presented in what follows.

Intelligent control methods have been used to study the problem of road roughness detection. For example, Gabrielli et al. [6] enhanced state of the art by introducing a Siamese Convolutional Neural Network architecture able to achieve improved results for the classification of the road surface roughness. Liu et al. [7] proposed a road roughness acquisition system design and an improved restricted Boltzmann machine deep neural network algorithm based on Adaboost Backward Propagation algorithm for road roughness detection to realize classification of different pavements. Liu et al. [8] developed an intelligent shift control method based on the identification of road roughness level.

In recent years, vehicle stability improvement by considering road roughness has been a subject undergoing intense studies. For example, Liu et al. [9] proposed a new method of constructing road roughness in left and right wheel paths based on Specified Power Spectral Density (PSD) and coherence function. Gorges et al. [10] presented an experimental validation of a road roughness classification method and proposed an impact detection strategy for twowheeled vehicles, including a classification of service loads, mild special events, and severe special events. Múčka et al. [11] presented original new results on measured whole-body vibration (WBV) on passenger's seat surface and seat base as a function of measured road unevenness in the longitudinal direction. Mastinu et al. [12] developed a new and relatively simple analytical model. Ma et al. [13] proposed a slip ratio controller based on model predictive control (MPC) considering road roughness for electric vehicle (EV) to improve the driving/braking performance. Múčka [14] analyzed measured vibration dose value (VDV) in passenger cars as a function of longitudinal road roughness.

Different estimation approaches have attracted the attention of research professionals. For example, Kang et al. [15] proposed a new road roughness estimation method by using the discrete Kalman filter with unknown input (DKFUI). Kansake and Frimpong [16] presented mathematical models for estimating tire dynamic forces on haul roads. Kim et al. [17] presented an improved discrete Kalman filter for simultaneously estimating both all state variables and the unknown road roughness input for a vehicle suspension control system that played a key role in the ride quality and handling performance while driving the vehicle. Hamersma and Els [18] addressed a priori knowledge needed by predicting what the suspension forces would be before changing the suspension setting.

Many researchers have focused on improving the comfort and vibrational response of the vehicle. For example, Liu and Cui [19] proposed a collaborative simulation algorithm for the performances between ride comfort and handling stability of a vehicle considering the connection and mutual influences. Jiang et al. [20] investigated the problem of interactive road roughness identification and proposed a novel inverse algorithm based on the knowledge of a vehicle dynamic characteristics and dynamic responses. Godbole et al. [21] aimed at understanding the likelihood of occurrence of vertical separation between the cargo and the trailer of a truck resulting from the amplified vertical vibrational response of the vehicle.

In the literature reviewed, most of the multi-DOF vehicle models were simplified. Some models ignored the effect of kinematic changes on the tire. A small number of researchers had focused on the nonlinear model, and they had usually neglected the effect on solving methods from dynamic simulation and low-amplitude vibration ride comfort. For some researchers, the response of the selected vehicles was different. For example, some of them did not consider the rationality of each vehicle response as an input, and the others did not consider the appropriate combination which was conducive to application in actual vehicles of vehicle responses as an input scheme.

This paper is dedicated to solving the problem of road roughness identification of different road level, providing a theoretical and methodological basis for road unevenness identification with the NARX neural network. It is different from static neural networks such as backpropagation (BP) neural network. Through feedback and memory, the NARX neural network can retain the data at the previous moment and add it to the calculation at the next moment. And also the NARX neural network can make the network be with dynamic characteristics and the system information be more complete greatly, improving the accuracy of road unevenness recognition and prediction.

In the paper, based on the 7-DOF vehicle vibration model, the NARX neural network is used to establish identification vehicle responses which can provide a theoretical and methodological basis for practical application of the NARX neural network to identify road roughness. The remainder of the paper is organized as follows. Section 2 presents the description of the NARX neural network. Section 3 provides the vehicle vibration model, and Section 4 presents the neural network design. In Section 5, the road roughness is identified based on NARX neural network. Finally, Section 6 concludes the paper and provides future research directions.

\section{NARX Neural Network}

2.1. Structure of the NARX Neural Network. NARX neural network is a classic dynamic neural network, which is composed of TDL delay layer, input layer, output layer, and hidden layer. The TDL delay layer delays the output of the neural network and feeds it back to the input layer to improve the prediction effect. The input layer concentrates the input and establishes weight and threshold operations on the input and then transfers the operation results to the hidden layer. The hidden layer can be one or more layers, which receives data, then calculates weights and thresholds, and finally transfers them to the output layer. The output layer compares the transferred calculation output with the expected output to obtain the error value and then corrects the weight, threshold, and the output data. The classic NARX neural network structure is shown in Figure 1.

The TDL performs c-order delay processing on input $x_{i}$ and output $y_{k}$. The number of input neurons is $n$; the hidden layer is 1 ; the number of the neurons in the hidden layer is $l$; 


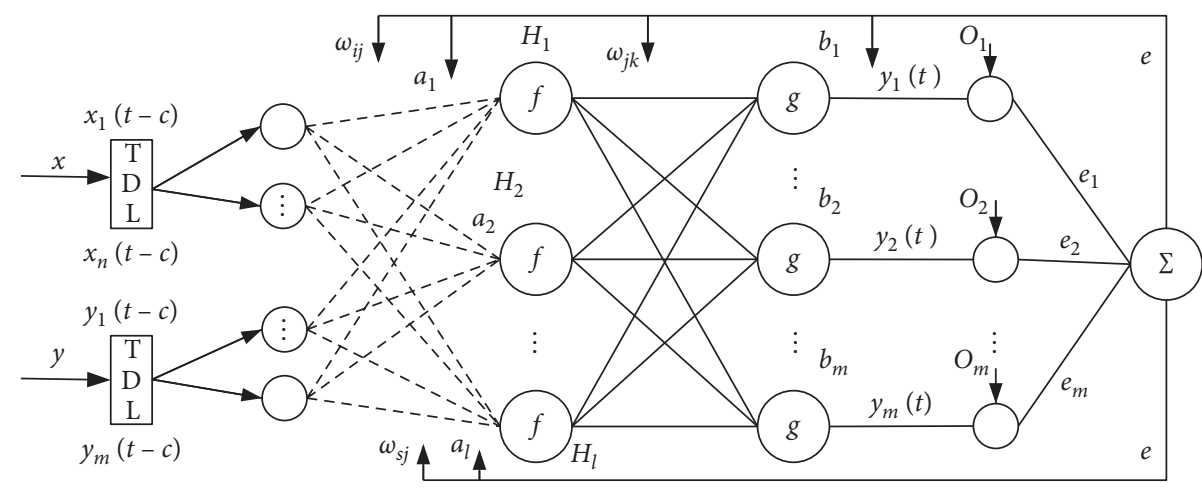

FIgURE 1: Typical NARX neural network structure.

the neuron in the output layer is $m$; the threshold of the hidden layer is $a_{j}$; the threshold of the output layer is $b_{k}$; and the expected output is $o_{k}$; the error between the expected output and the calculated output is $e_{k}$. The weight between the input layer and the hidden layer is $\omega_{i j}$; the weight between the output delay layer and the hidden layer is $\omega_{s j}$; the weight between the hidden layer and the output layer is $\omega_{j k}$.

2.2. NARX Neural Network Structure Design. The number of neurons in the time delay layer, input layer, and output layer of the NARX neural network is determined by the input and output of the actual problem. Generally, the output is only delayed once.

In practical applications, the hidden layer is generally taken as one layer, and the number $l$ of neuron nodes in the hidden layer is [22]

$$
l=\sqrt{(m+n)}+a,
$$

where $a$ is a constant between 0 and 10; $m$ is the neuron in the output layer; and $n$ is the number of input neurons.

Generally, the transfer function $f$ of the hidden layer is set as logsig, and the transfer function $g$ of the output layer is set as purelin:

$$
\left\{\begin{array}{l}
f(x)=\frac{1}{\left(1+e^{-x}\right)}, \\
g(x)=x .
\end{array}\right.
$$

The weights and thresholds of the neural network are adjusted by the training algorithm. The NARX neural network has 14 training algorithms. The default training algorithm is trainlm, which has fast training speed and high identification accuracy [22].

When evaluating the performance of the NARX neural network for road roughness identification results, the paper provides two commonly used evaluation indicators in neural network research [23], which are the correlation coefficient $(R)$ and the root mean square error (RMSE). $R$ refers to the degree of linear correlation between the identified road roughness and the ideal road roughness when the neural network input is given. The higher $R$, the better the identification effect. The range of $R$ is $(-1,1)$. If $R$ is positive, it is a positive correlation; otherwise, it is a negative correlation. According to the $R$ standard, the absolute value of $R$ can be divided into $0.0 \sim 0.2,0.2 \sim 0.4,0.4 \sim 0.6,0.6 \sim 0.8$, and $0.8 \sim 1.0$ levels, which are, respectively, corresponding to extremely weak correlation or irrelevance, weak correlation, medium degree correlation, strong correlation, and extremely strong correlation.

The calculation formula of $R$ is

$$
R=\frac{\sum_{i=1}^{n}\left(y_{i}-\bar{y}\right)\left(a_{i}-\bar{a}\right)}{\sqrt{\sum_{i=1}^{n}\left(y_{i}-\bar{y}\right)^{2}} \sqrt{\sum_{i=1}^{n}\left(a_{i}-\bar{a}\right)^{2}}}
$$

where $y_{i}$ and $a_{i}$ are the $i^{\text {th }}$ points of the identified and expected road roughness, respectively; $\bar{a}$ are the average values of the identified and expected road roughness respectively; and $n$ is the number of sample points.

RMSE that is known as the standard error is the arithmetic square root of variance. In the process of data training and debugging, the programmed neural network will produce certain random errors. RMSE can reflect the stability of the network identification result. The smaller the value, the more stable and reliable the identification result.

The calculation formula of RMSE is

$$
\text { RMSE }=\frac{\sqrt{\sum_{i=1}^{n}\left(a_{i}-y_{i}\right)^{2}}}{n} .
$$

\section{Vehicle Vibration Model}

A simplified 7-DOF planar model including the vertical, roll, and pitch movement of the body is shown in Figure 1. And the parameters are shown in Table 1.

To establish the 7-DOF vehicle dynamic model, the following assumptions must be made firstly:

(i) The body is regarded as a rigid body with concentrated mass; only the influence of vertical, roll, and pitch vibrations of the body on the ride comfort is considered; the influence of torsional vibration of the body on the ride comfort is ignored

(ii) It is assumed that the body is a linear system 
Table 1: Parameters.

\begin{tabular}{|c|c|}
\hline Parameter & Symbol \\
\hline Body mass & $m$ \\
\hline Front wheel mass & $m_{1}$ and $m_{2}$ \\
\hline Rear wheel mass & $m_{3}$ and $m_{4}$ \\
\hline Displacement of the body mass in the vertical direction & $z_{\mathrm{c}}$ \\
\hline Yaw moment of inertia around the $x$-axis & $I_{x}^{c}$ \\
\hline Yaw moment of inertia around the $y$-axis & $I_{y}$ \\
\hline Distance of center of gravity to front axle & $a$ \\
\hline Distance of center of gravity to rear axle & $b$ \\
\hline Displacement excitation of the road affecting the left front tire & $z_{01}$ \\
\hline Displacement excitation of the road affecting the right front tire & $z_{02}$ \\
\hline Displacement excitation of the road affecting the left rear tire & $z_{03}$ \\
\hline Displacement excitation of the road affecting the right rear tire & $z_{04}$ \\
\hline Synthesized stiffness of front tire & $k_{1}$ and $k_{3}$ \\
\hline Synthesized stiffness of rear tire & $k_{5}$ and $k_{7}$ \\
\hline Stiffness of front suspension & $k_{2}$ and $k_{4}$ \\
\hline Stiffness of rear suspension & $k_{6}$ and $k_{8}$ \\
\hline Track base of the vehicle & $L$ \\
\hline Displacement of the left front wheels in the vertical direction & $z_{1}$ \\
\hline Displacement of the right front wheels in the vertical direction & $z_{2}$ \\
\hline Displacement of the left rear wheels in the vertical direction & $z_{3}$ \\
\hline Displacement of the right rear wheels in the vertical direction & $z_{4}$ \\
\hline Vertical displacement of body centroid & $z_{5}$ \\
\hline Roll angle displacement of the body & $z_{6}$ \\
\hline Pitch angle displacement of the body & $z_{7}$ \\
\hline Equivalent damping coefficient of front tire & $c_{1}$ and $c_{3}$ \\
\hline Equivalent damping coefficient of rear tire & $c_{5}$ and $c_{7}$ \\
\hline Equivalent damping coefficient of front suspension & $c_{2}$ and $c_{4}$ \\
\hline Equivalent damping coefficient of rear suspension & $c_{6}$ and $c_{8}$ \\
\hline
\end{tabular}

(iii) The vehicle is symmetrical along the longitudinal centerline and moves in a straight line at a constant speed

(iv) The road surface is isotropic

(v) Other vibration sources except the road surface are ignored

According to the Lagrange equation, the vibration equation of the vehicle can be obtained as follows (Figure 2):

$$
M \ddot{Z}+C \dot{Z}+K Z=K_{t} Q+C_{t} \dot{Q},
$$

where $M$ is the mass matrix of the vehicle; $C$ is the damping matrix of the vehicle; $K$ is the stiffness matrix of the vehicle; $Z$ is the displacement vector corresponding to the vehicle's respective degrees; $Q$ is the pavement input vector; $K_{t}$ is the stiffness matrix of the tire; $C_{t}$ is the damping matrix of the tire:

$$
\begin{aligned}
& M=\operatorname{diag}\left[\begin{array}{lllllll}
m_{1} & m_{2} & m_{3} & m_{4} & m & I_{x} & I_{y}
\end{array}\right], \\
& Z=\left[\begin{array}{lllllll}
z_{1} & z_{2} & z_{3} & z_{4} & z_{5} & z_{6} & z_{7}
\end{array}\right]^{T}, \\
& \mathrm{Q}=\left[\begin{array}{llll}
z_{01} & z_{02} & z_{03} & z_{04}
\end{array}\right]^{T}, \\
& K_{t}=\left[\begin{array}{cccc}
k_{1} & 0 & 0 & 0 \\
0 & k_{3} & 0 & 0 \\
0 & 0 & k_{5} & 0 \\
0 & 0 & 0 & k_{7} \\
0 & 0 & 0 & 0 \\
0 & 0 & 0 & 0 \\
0 & 0 & 0 & 0
\end{array}\right],
\end{aligned}
$$




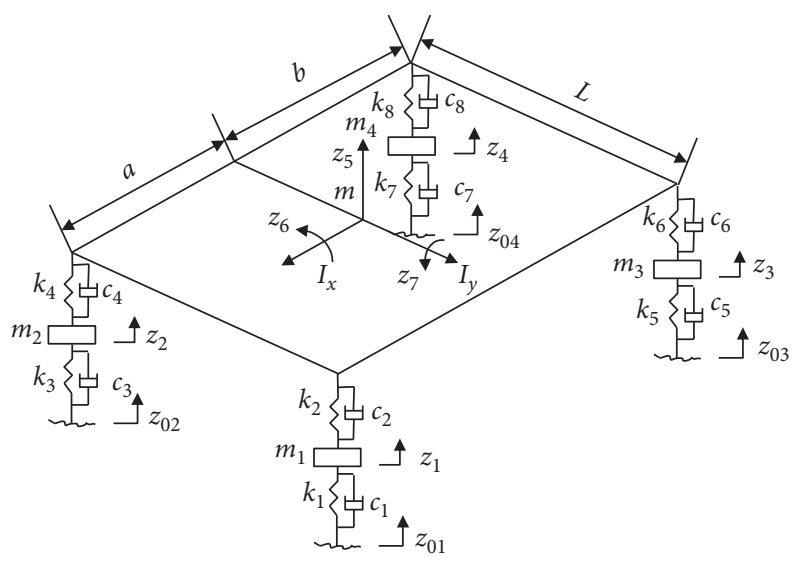

FIgURE 2: 7-DOF vehicle vibration model.

$C_{t}=\left[\begin{array}{cccc}c_{1} & 0 & 0 & 0 \\ 0 & c_{3} & 0 & 0 \\ 0 & 0 & c_{5} & 0 \\ 0 & 0 & 0 & c_{7} \\ 0 & 0 & 0 & 0 \\ 0 & 0 & 0 & 0 \\ 0 & 0 & 0 & 0\end{array}\right]$

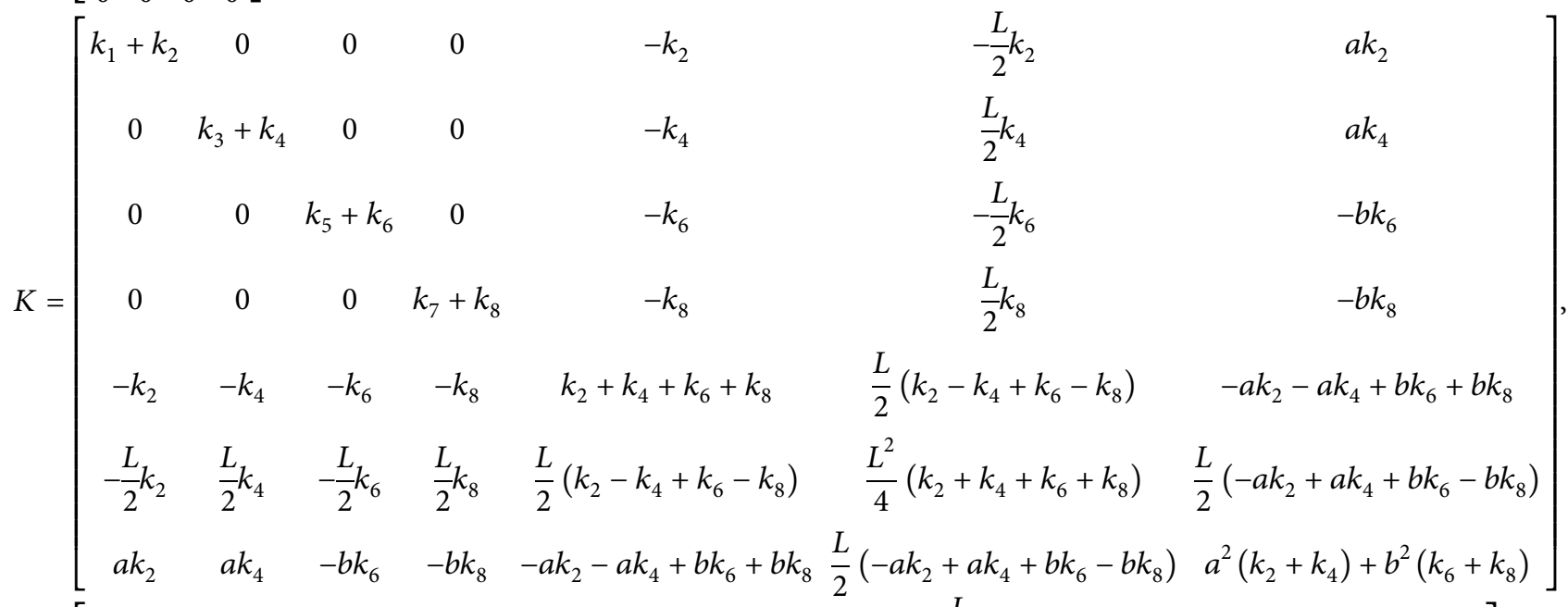

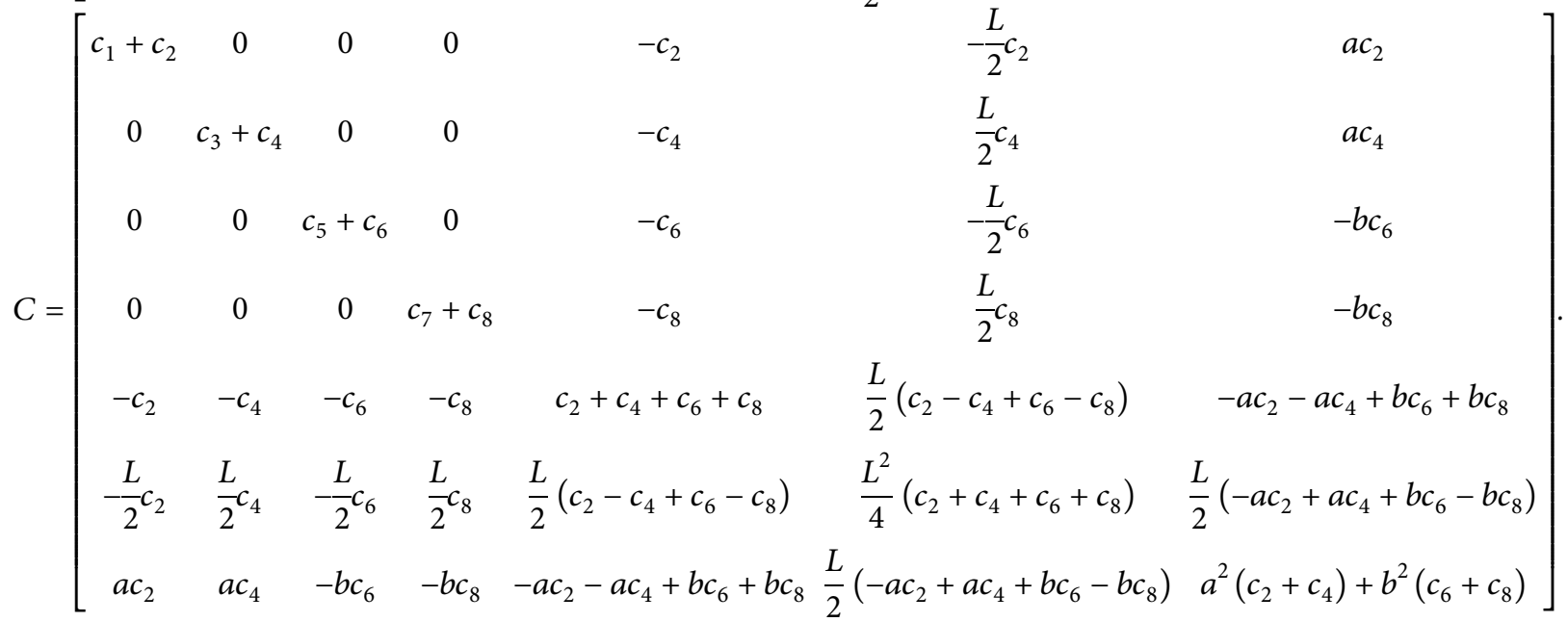




\section{Neural Network Design}

It is assumed that the input white noise of one wheel track $x$ is $W_{x}$, and the input white noise of the other wheel track $y$ is $W_{y}$. According to the random vibration theory, for a linear system, when the input is a stable process, the output is also a stable process. In this way, the problem can be virtualized as follows: giving one input of the wheel track and finding the output of another wheel track. And the input and output are connected by the coherence function $\operatorname{coh}_{x y}(f)$. That is, the transfer relationship between the left and right wheels is established, and another random process of the wheel track is derived from the given random process.

The front wheel is set as the reference point, and the transfer function of the white noise input $W_{x}$ and $W_{y}$ between the left and right wheels is

$$
G_{x y}=\frac{W_{y}(s)}{W_{x}(s)}=\frac{a_{0}+a_{1} s+\cdots+a_{n} s^{n}}{b_{0}+b_{1} s+\cdots+b_{n} s^{n}},
$$

where $W_{x}(s)$ and $W_{y}(s)$ are the road white noise input under the left and right wheels.

Then, equation (8) can be obtained by taking the 2-order approximation:

$$
G_{x y}=\frac{a_{0}+a_{1} s+a_{2} s^{2}}{b_{0}+b_{1} s+b_{2} s^{2}}
$$

where the coefficients are obtained by fitting and transforming the measured coherence functions of different roads.

Equation (9) can be obtained by introducing the intermediate variable $M(s)$ :

$$
G_{x y}=\frac{W_{y}(s)}{W_{x}(s)}=\frac{\left(a_{0} s^{-2}+a_{1} s^{-1}+a_{2}\right) M(s)}{\left(b_{0} s^{-2}+b_{1} s^{-1}+b_{2}\right) M(s)},
$$

where $M(s)$ is an intermediate variable.

Then, equations (10) and (11) can be obtained from the numerator and denominator, respectively:

$$
\begin{array}{r}
W_{x}(s) M(s)=\left(b_{0} s^{-2}+b_{1} s^{-1}+b_{2}\right) M(s), \\
W_{y}(s)=\left(a_{0} s^{-2}+a_{1} s^{-1}+a_{2}\right) M(s) .
\end{array}
$$

It is set that $x_{1}=L^{-1}\left(s^{-1} M(s)\right)$ and $x_{2}=L^{-1}\left(s^{-2} M(s)\right)$. At the same time, because $L\left[\dot{x}_{2}\right]=s \cdot L\left[x_{2}\right]=$ $s \cdot s^{-2} M(s)=s^{-1} M(s)=L\left[x_{1}\right], \dot{x}_{2}=x_{1}$.

The correlation state equation of the two wheels is obtained by taking inverse Laplace transform on equation (10) and combining with $\dot{x}_{2}=x_{1}$ :

$$
\left[\begin{array}{c}
\dot{x}_{1} \\
\dot{x}_{2}
\end{array}\right]=\left[\begin{array}{cc}
-\frac{b_{1}}{b_{2}} & -\frac{b_{0}}{b_{2}} \\
1 & 0
\end{array}\right]\left[\begin{array}{l}
x_{1} \\
x_{2}
\end{array}\right]+\left[\begin{array}{c}
\frac{1}{b_{2}} \\
0
\end{array}\right] W_{x}
$$

Similarly, the output equation can be obtained by performing inverse Laplace transform on equation (11).

$$
W_{y}=a_{2} \dot{x}_{1}+a_{0} x_{2}+a_{1} x_{1}
$$

Then, equation (14) can be obtained by substituting $\dot{x}_{1}$ into equation (13)

$$
W_{y}=\left[a_{1}-a_{2} \frac{b_{1}}{b_{2}} a_{0}-a_{2} \frac{b_{0}}{b_{2}}\right]\left[\begin{array}{l}
x_{1} \\
x_{2}
\end{array}\right]+\left[\frac{a_{2}}{b_{2}}\right] W_{x} .
$$

When the road surface is generated, it is possible to obtain the white noise input $W_{y}$ of another wheel track through the intermediate state variables $x_{1}$ and $x_{2}$ of equation (12) while generating one wheel track $W_{x}$. And then, according to equation (13), the space correlation timedomain model of the first and second wheel tracks can be obtained.

The road surface roughness, which is the input of vehicle vibration, mainly uses the road surface power spectrum density to describe its statistical characteristics. According to ISO/TC108/SC2N67, the classification standard of different road level is shown in Table 2 .

$G_{q}\left(n_{0}\right) /\left(10^{-6} m^{3}\right)$ is the power spectrum density.

For the simulation, the initial values of the weights $\omega_{i j}$, $\omega_{j k}$, and $\omega_{s j}$ and thresholds $a_{j}$ and $b_{k}$ are set as a random number between $[0,1]$. And the maximum number of iteration is set as 1000 .

The NARX neural network is programmed by MATLAB software. First, the input and target output of the training set are imported into the neural network program. The hidden layer is a single layer, the number of neurons in the input layer is 7 , and the number of neurons in the output layer is 1 . The simulation time is $12.5 \mathrm{~s}$, and the sampling interval is $0.01 \mathrm{~s}$. The number of sampling points is 1250 . The front wheel road surface unevenness of 850 points is used as the output of the training set, and the other front wheel road surface unevenness of 400 points is used as the output of the test set to determine the effect of neural network recognition.

In order to verify that the algorithm is valid, the solution is calculated by MATLAB software in a computer whose $\mathrm{CPU}$ is $2.8 \mathrm{GHz} /$ Pentium IV and the operating system is Window XP.

And the parameters are $m=920 \mathrm{~kg}, I_{y}=948 \mathrm{~kg} \mathrm{~m}^{2}$, $I_{x}=239 \mathrm{~kg} \mathrm{~m}^{2}, a=1.109 \mathrm{~m}, b=1.09 \mathrm{~m}, L=1.22 \mathrm{~m}, m_{1}=m_{2}$ $=m_{3}=m_{4}=25 \mathrm{~kg}, \quad c_{1}=c_{3}=c_{5}=c_{7}=40 \mathrm{~N} \cdot \mathrm{s} / \mathrm{m}, \quad k_{2}=k_{4}=$ $16.7 \mathrm{kN} / \mathrm{m}, k_{6}=k_{8}=21.1 \mathrm{kN} / \mathrm{m}, c_{6}=c_{8}=3340 \mathrm{~N} \cdot \mathrm{s} / \mathrm{m}, c_{2}=c_{4}$ $=2845 \mathrm{~N} \cdot \mathrm{s} / \mathrm{m}$, and $k_{1}=k_{3}=k_{5}=k_{7}=147 \mathrm{kN} / \mathrm{m}$.

The unevenness excitations of a vehicle on the B- level and C-level roads are shown in Figures 3-6. It can be seen from the figures that the unevenness of the C-level road is larger than that of the B-level road. And there is a time delay in the unevenness of the front and rear wheels.

\section{Road Roughness Identification Based on NARX Neural Network}

In this paper, based on the 7-DOF vehicle dynamic model, the road roughness identification technology is studied. Among the dynamic responses of the vehicle, the vehicle response that is reasonable and has a significant impact on 
TABLE 2: Classification standard of road level.

\begin{tabular}{lccc}
\hline Road level & Lower limit & $G_{q}\left(n_{0}\right) /\left(10^{-6} \mathrm{~m}^{3}\right)$ & Upper limit \\
\hline B & 32 & Geometric mean & 128 \\
C & 128 & 64 & 512 \\
\hline
\end{tabular}

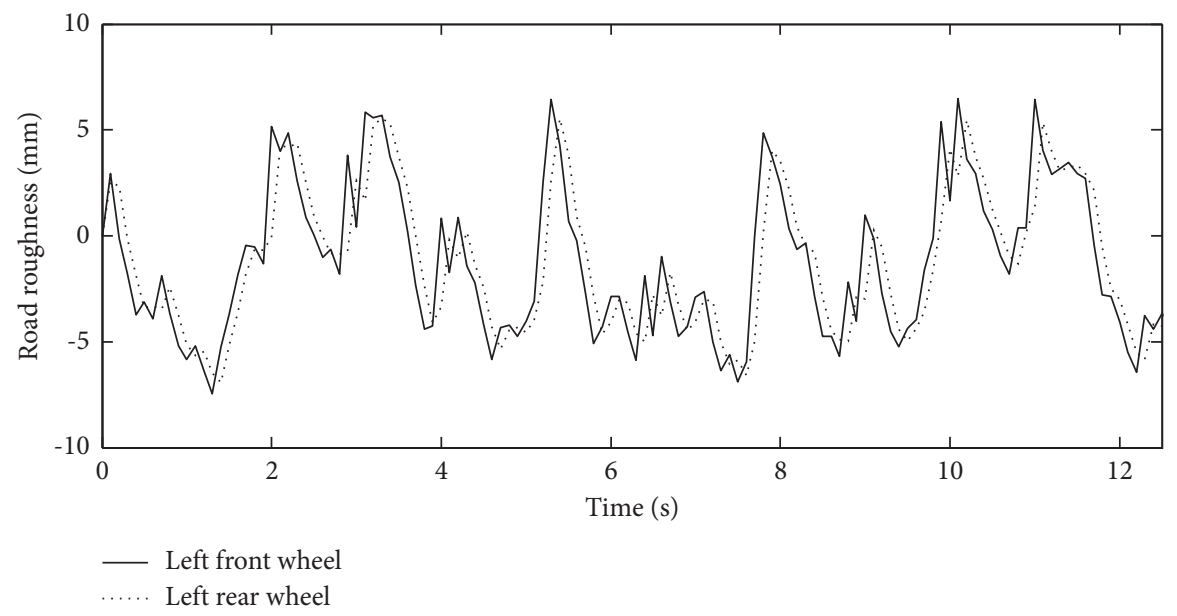

FIgURE 3: Road roughness of the left front and rear wheels (B-level).

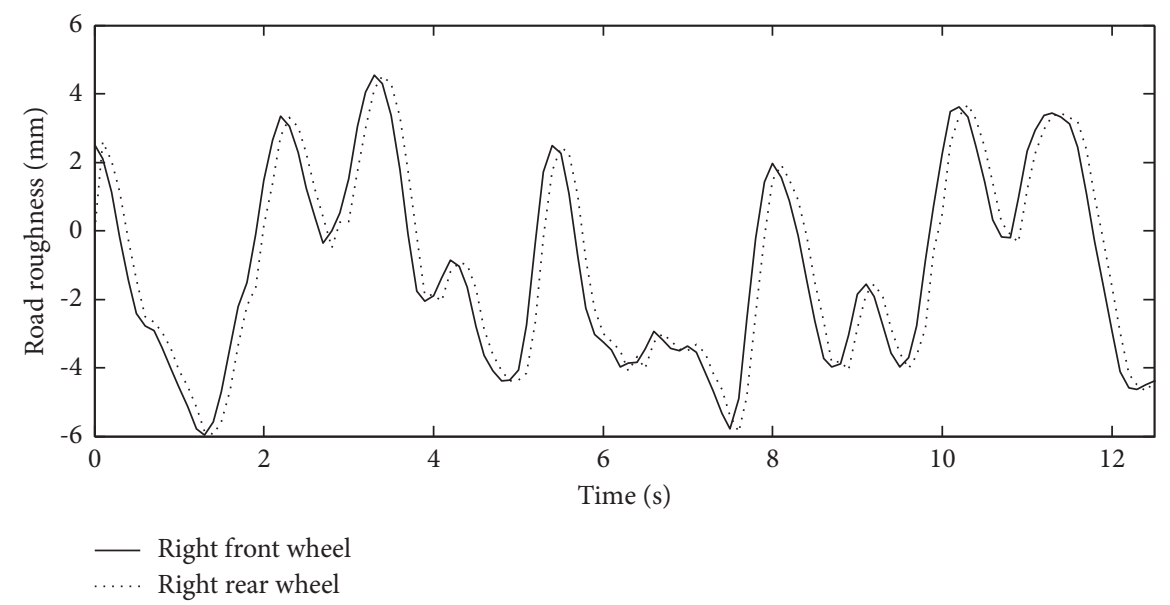

FIGURE 4: Road roughness of the right front and rear wheels (B-level).

the identification result is selected, and the repeated vehicle responses are removed to establish a nonlinear relationship between input and output data in the NARX neural network. The NARX neural network is programmed by MATLAB software. Firstly, the input and target output of the training set are imported into the neural network program, and then the input and output are set as $1: 2$.

5.1. Simulation Results of B-Level Road Roughness. According to the 7-DOF vehicle data, the MATLAB software is used for programming, and the vertical acceleration and elevation angular acceleration of the body of the B-level road surface, which are substituted to the trained network for calculation, are simulated as shown in Figures 7 and 8, respectively.
Figure 9 shows the result of the NARX network identifying the road surface excitation of the left front wheel on the B-level road. Figure 10 shows the relative error between the identification value and the fitted value of the filtered white noise. Figures 11 and 12 are the simulation results after adding noise. It can be seen that the relative error is small, the antinoise ability is strong, and the identification accuracy is higher.

5.2. Simulation Results of C-Level Road Roughness. According to the 7-DOF vehicle data, the MATLAB software is used for programming, and the vertical acceleration and elevation angular acceleration of the body of the C-level road surface, which are substituted to the trained network for 


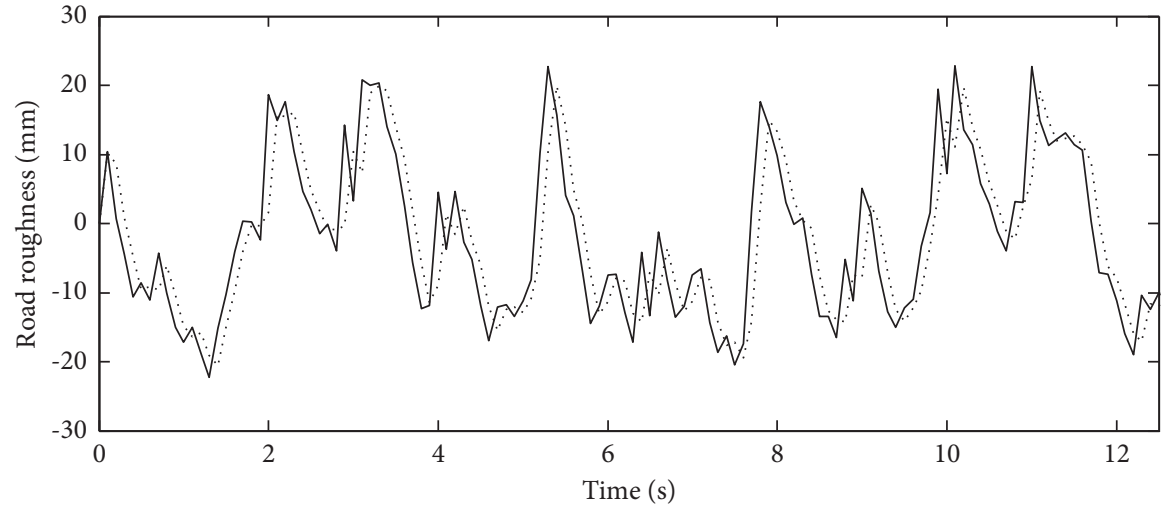

- Left front wheel

...... Left rear wheel

FIgURE 5: Road roughness of the left front and rear wheels (C-level).

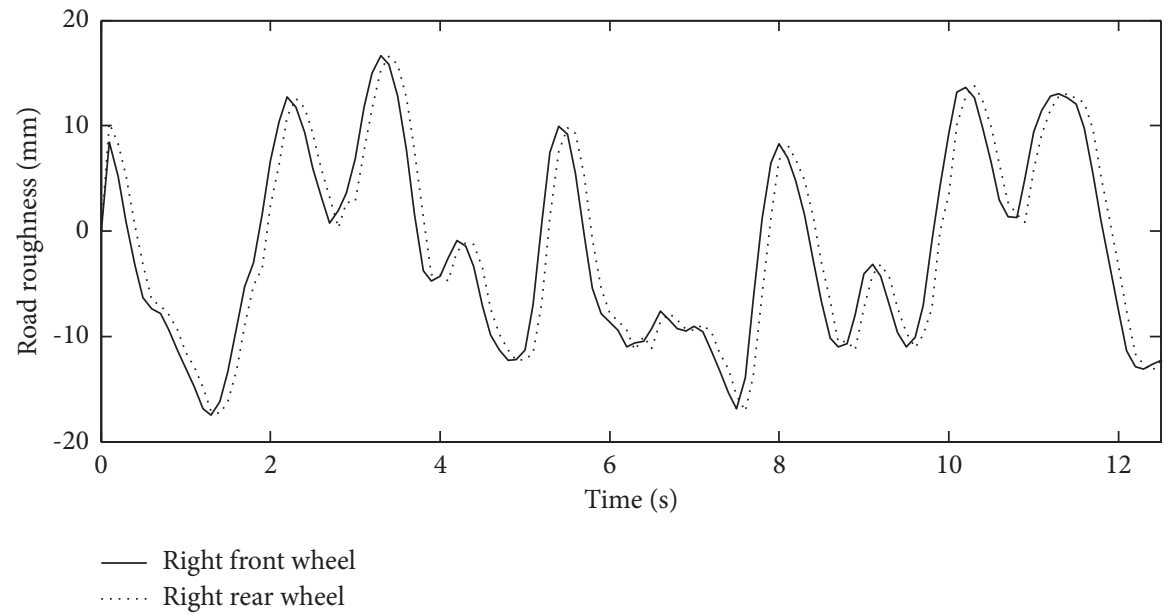

Figure 6: Road roughness of the right front and rear wheels (C-level).

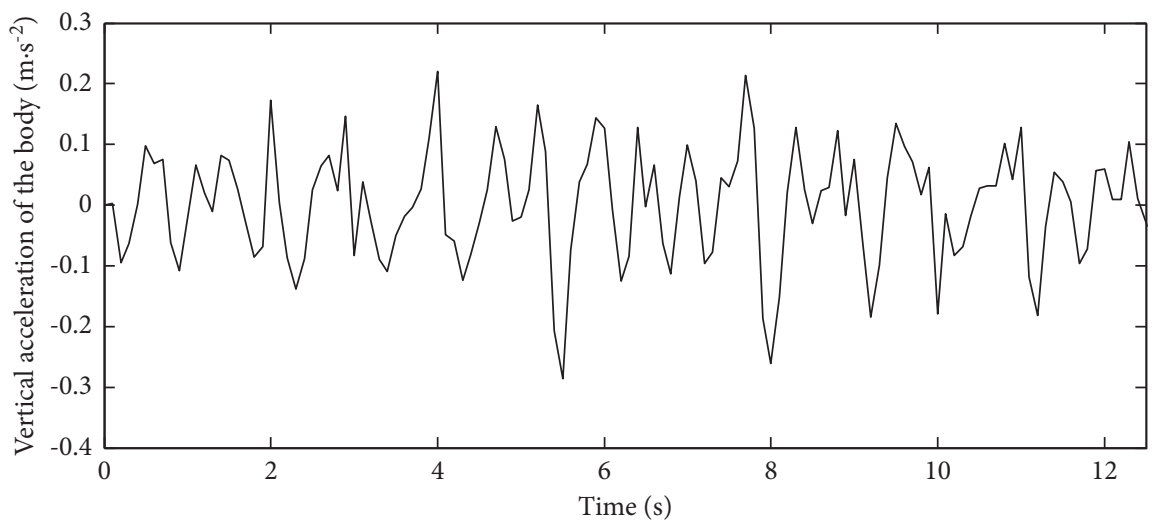

FIgURE 7: Vertical acceleration of the body of B-level road surface. 


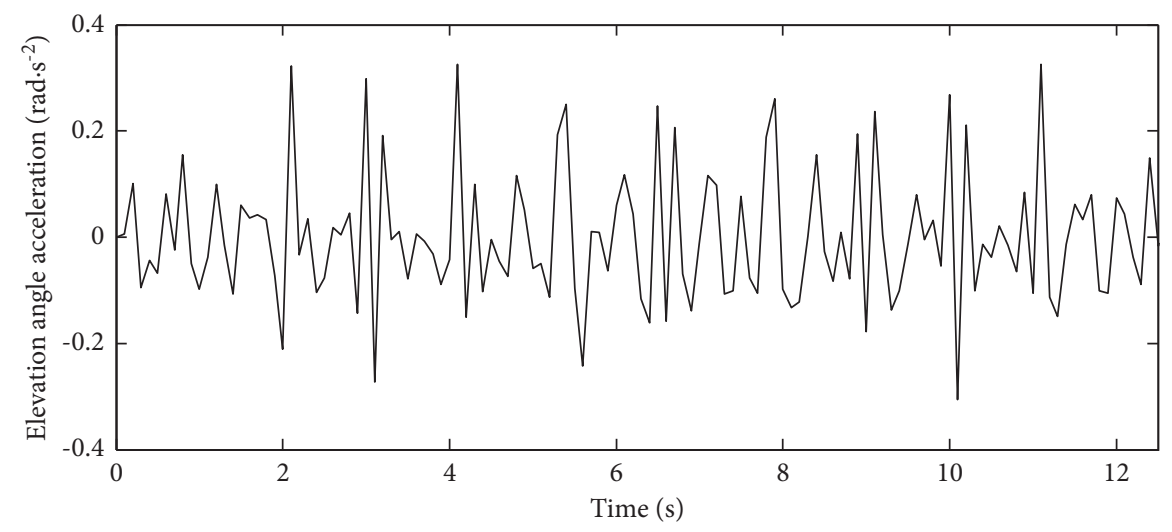

FIgURE 8: Elevation angular acceleration of B-level road surface.

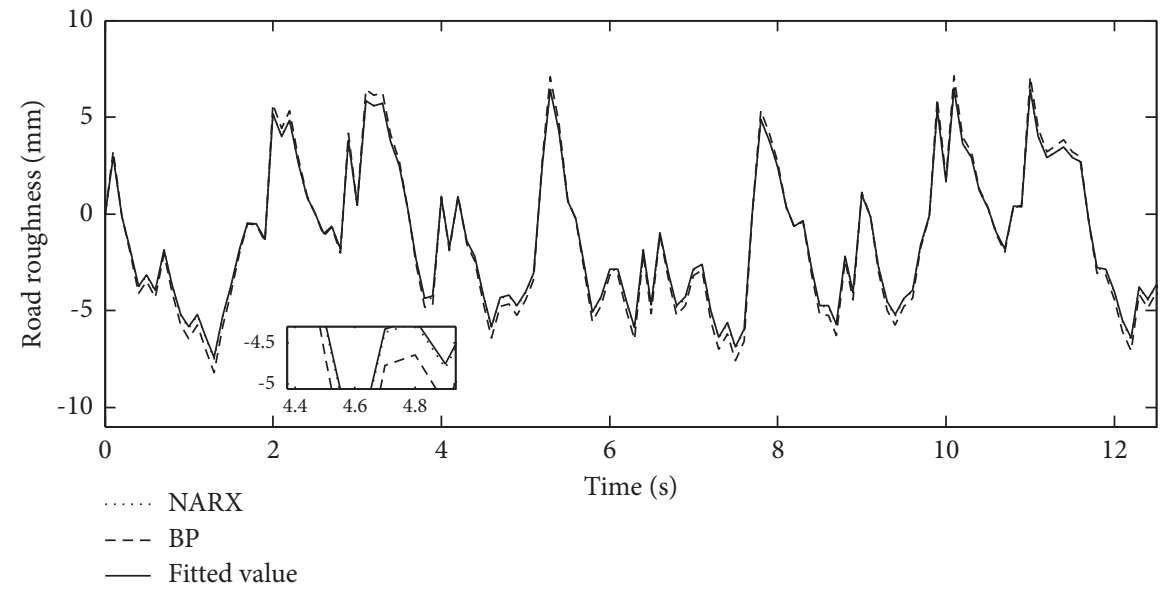

Figure 9: Identification and fitted values of road roughness (without noise).

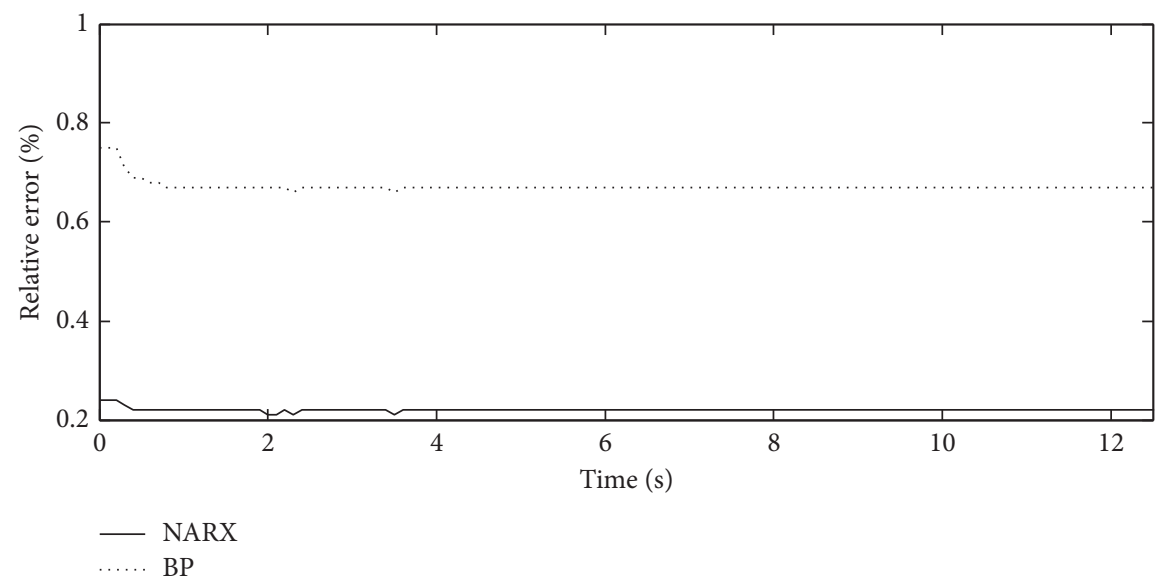

FIGURE 10: Relative error of road roughness (without noise).

calculation, are simulated as shown in Figures 13 and 14, respectively.

Figure 15 shows the result of the NARX network identifying the road surface excitation of the left front wheel on the C-level road. Figure 16 shows the relative error between the identification value and the fitted value of the filtered white noise. Figures 17 and 18 are the simulation results after adding noise. From the figures, it can be seen that the identification accuracy is higher.

The evaluation index values for different road levels are shown in Table 3.

It can be seen from Table 3 that the NARX neural network has an ideal identification effect on different levels of roads. It can be seen from the table that $R$ has reached 


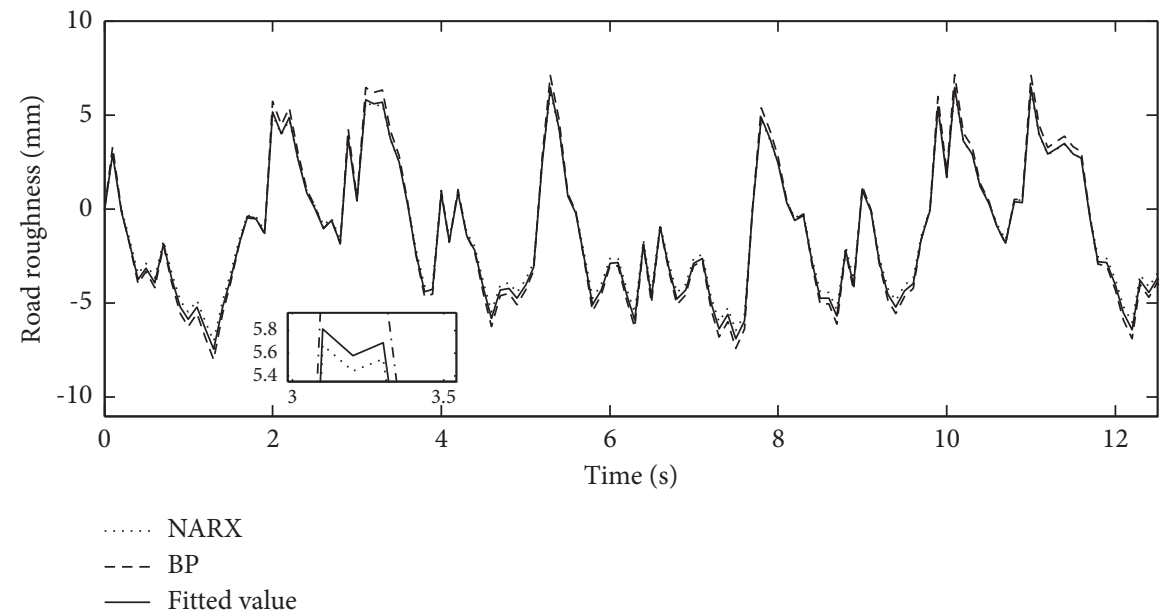

FIGURE 11: Identification and fitted values of road roughness (with noise).

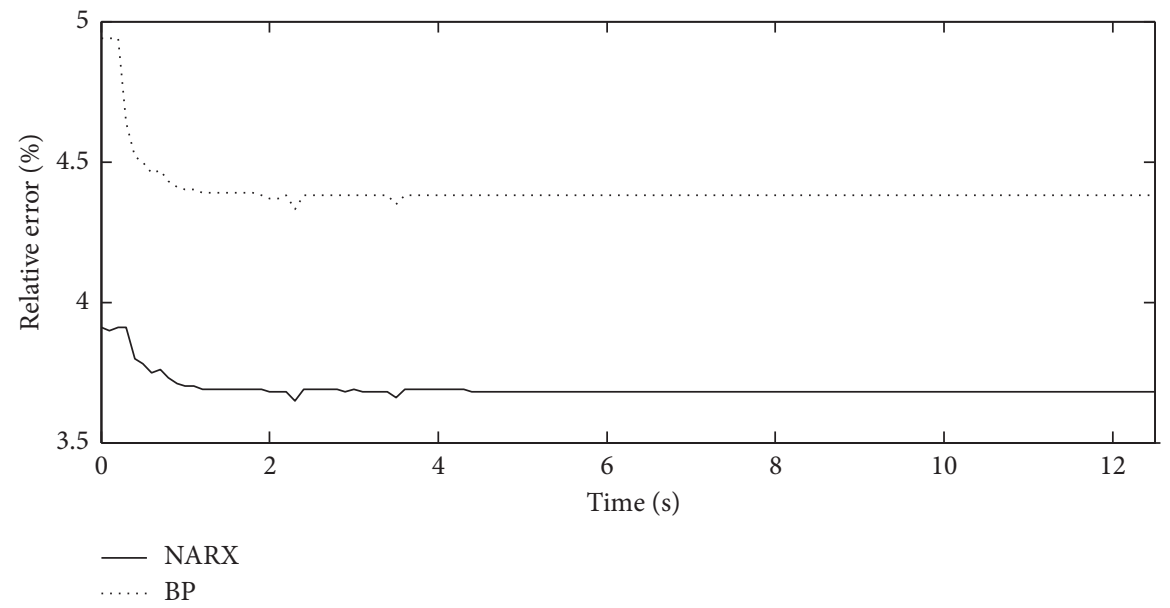

FIGURE 12: Relative error of road roughness (with noise).

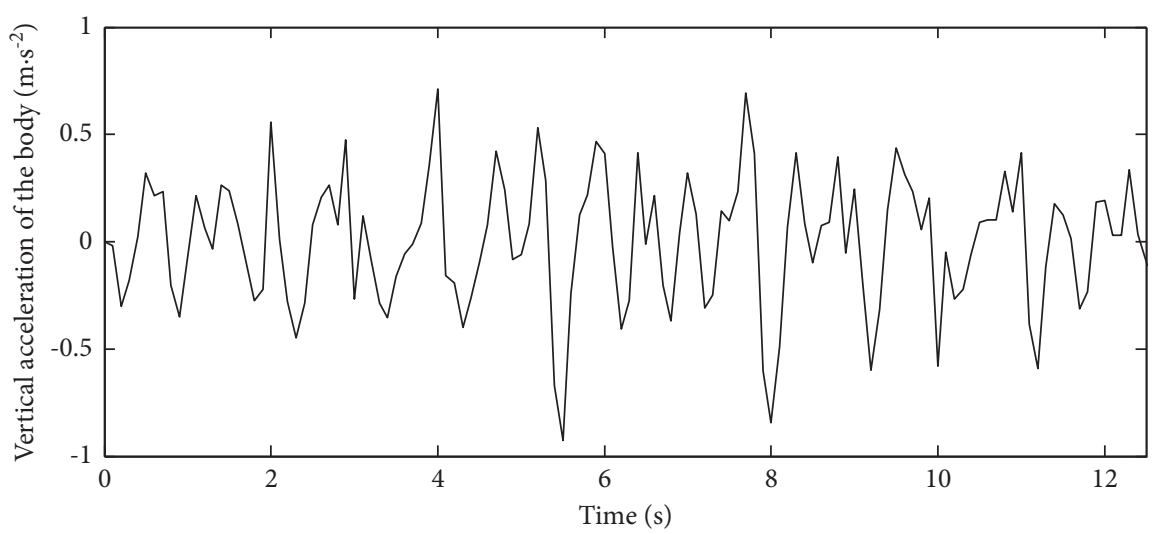

FIGURE 13: Vertical acceleration of the body of C-level road surface. 


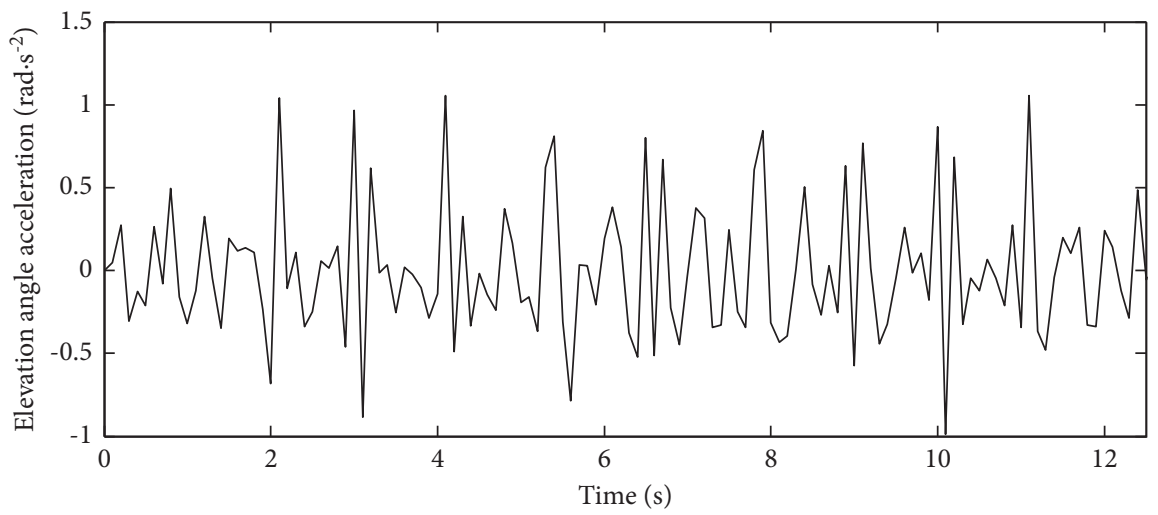

FIgURE 14: Elevation angular acceleration of C-level road surface.

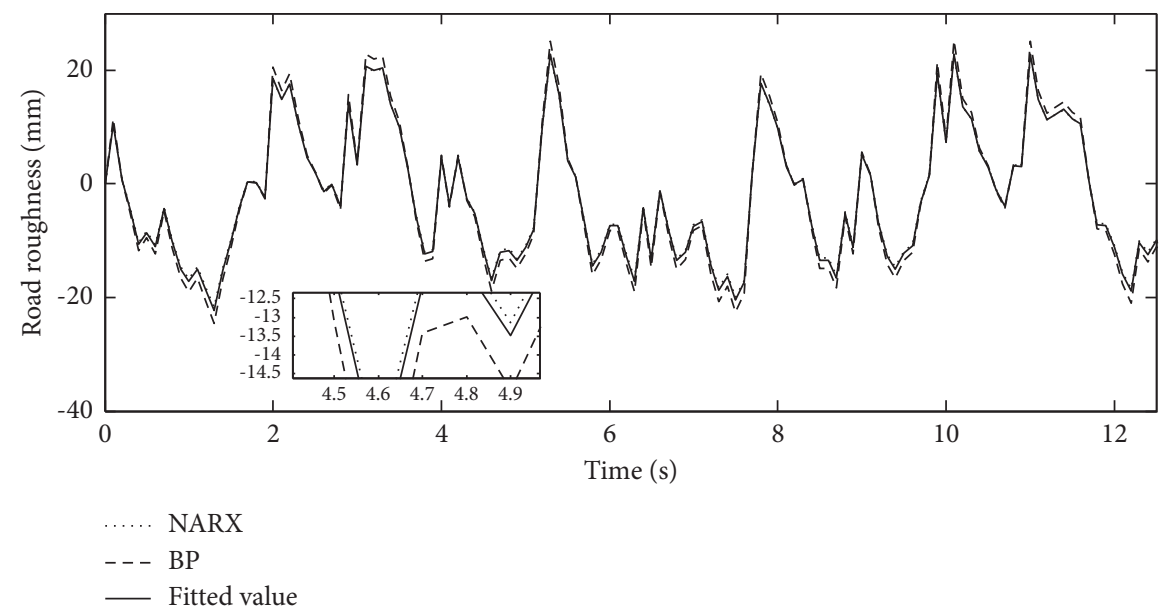

Figure 15: Identification and fitted values of road roughness (without noise).

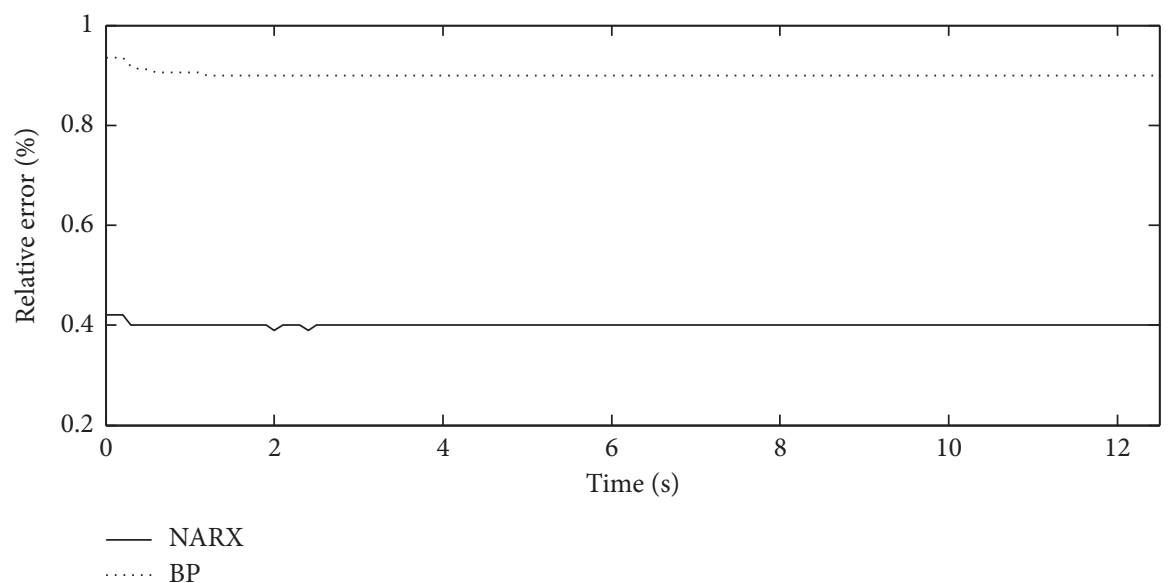

Figure 16: Relative error of road roughness (without noise). 


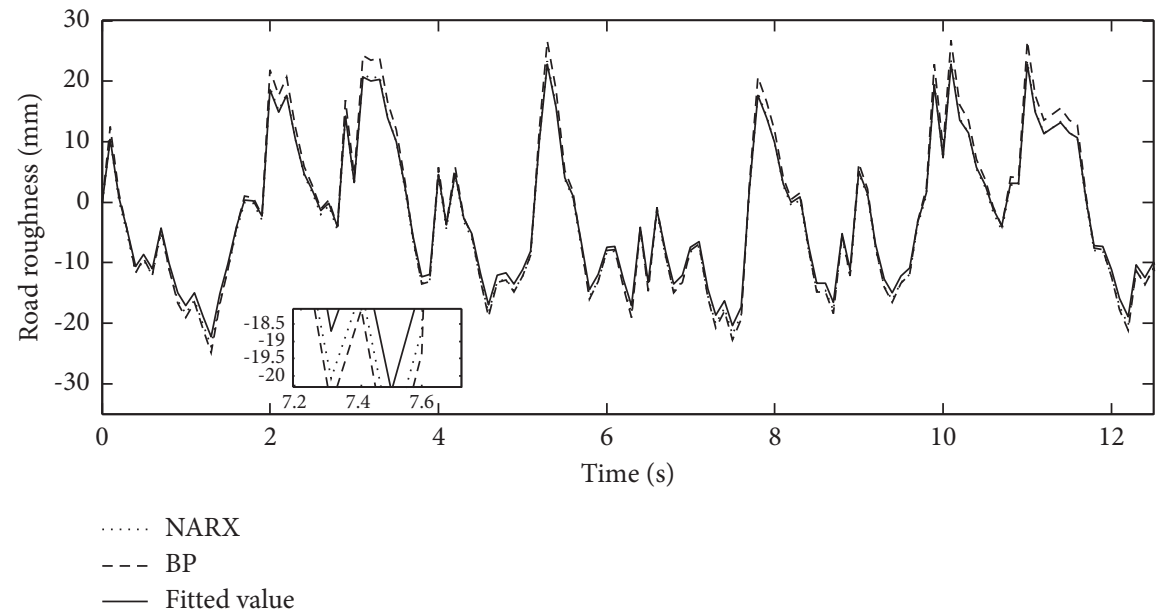

FIGURE 17: Identification and fitted values of road roughness (with noise).

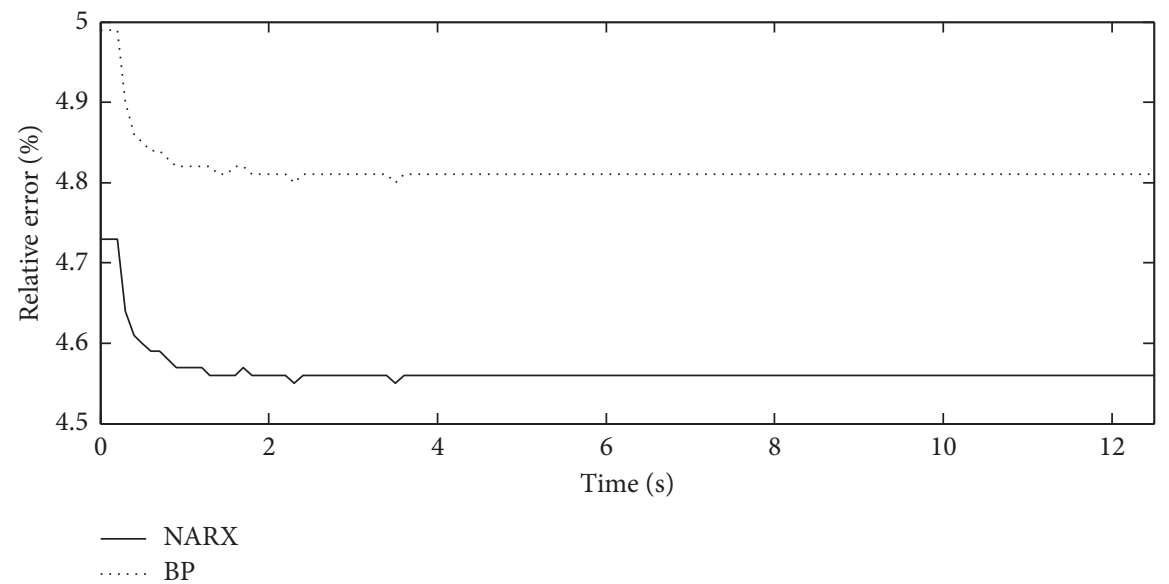

FIgURE 18: Relative error of road roughness (with noise).

TABLE 3: Evaluation index values for different road levels.

\begin{tabular}{lcc}
\hline Road level & $R / \%$ & RMSE \\
\hline B & 95.690 & 0.0085 \\
C & 92.380 & 0.0268 \\
\hline
\end{tabular}

more than $90 \%$, indicating that the actual road roughness identification is very consistent with the expected road roughness.

And also, compared with the traditional method (BP neural network), the results indicate that the NARX neural network has better recognition accuracy than that of the BP neural network for road roughness identification.

5.3. Test Verification Based on ADAMS/View. The virtual test system not only can be used as the preparatory work for the real test but also can replace the traditional test to a certain extent. Compared with traditional tests, it has the following advantages:

(i) It can greatly reduce the number of prototype manufacturing tests and shorten the new product test cycle. At the same time, the cost of actual testing is reduced

(ii) The application of virtual test technology in the development of complex products can realize the mutual feedback of information between designers and product users in the design phase so that designers can absorb and adopt suggestions for new products in all aspects

(iii) The virtual test technology replaces the actual test, and the test process can be repeated

Due to the limitations of real vehicle test conditions and the fact that the ADAMS virtual test has the above advantages, the paper uses the ADAMS/View virtual simulation test instead of the real vehicle test to verify the neural network identification method. 


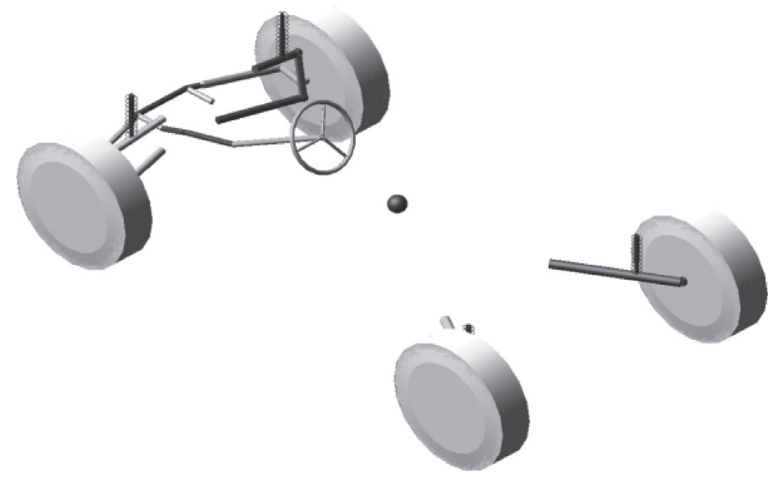

Figure 19: Vehicle model based on ADAMS/View.

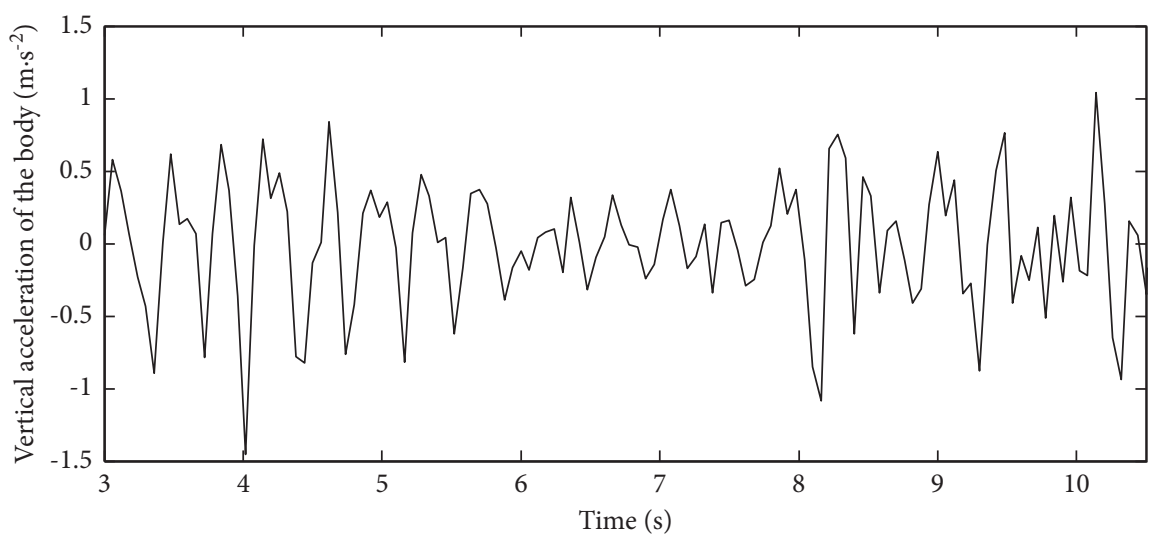

Figure 20: Vertical acceleration of the body of C-level road surface.

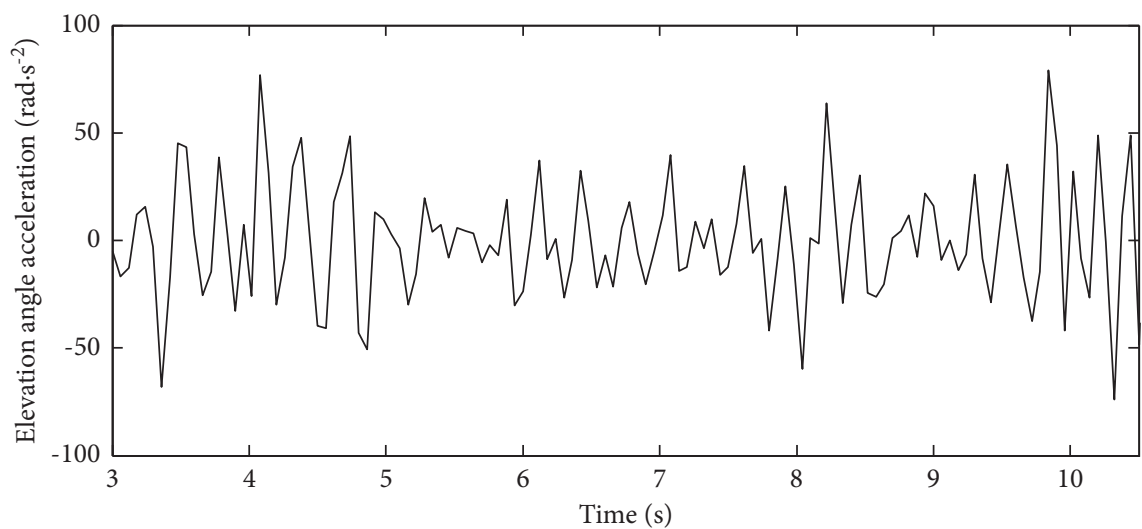

FIgURE 21: Elevation angular acceleration of C-level road surface.

A vehicle is a complex vibration system. Generally, different types of simplified modeling of the vehicle system are required according to the research objectives and actual effects when analyzing the driving comfort and handling stability of the vehicle. The vehicle model mainly includes vehicle body model, double-wishbone front independent suspension model, steering mechanism model, inclined arm rear suspension model, tire model, and road surface spectrum.
In the process of vehicle modeling, the following simplifications and assumptions are made for each component model:

(i) The body part does not need to be modeled according to the actual structure and is integrated into a rigid body

(ii) The sprung mass is integrated into the body rigid body 


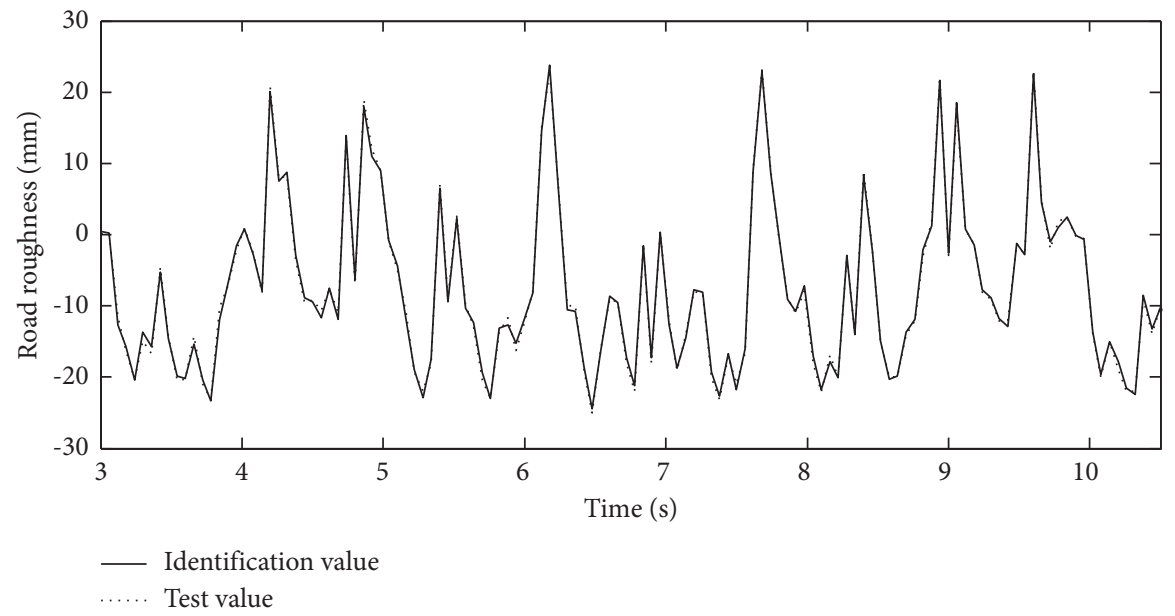

FIgURE 22: Identification and test values of C-level road roughness.

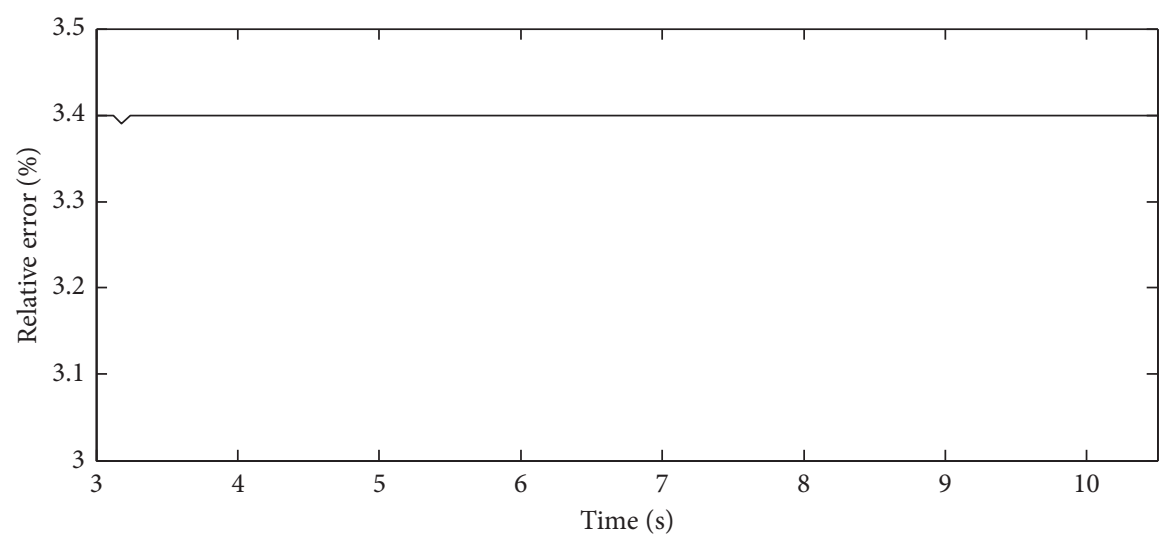

FIgURE 23: Relative error of C-level road roughness.

(iii) The tires, dampers, springs, rubber components, and so on are deformable, and the other parts are regarded as rigid bodies

(iv) The friction between the motion pairs is ignored

The body is simplified into a rigid body, and the mass is concentrated in the center of mass. Since the paper mainly researches the road roughness identification of the vehicle, the specific structure of other parts such as the engine and brake assembly is ignored. It adopts a double-wishbone independent suspension model, which is mainly composed of kingpin, upper and lower wishbone, pull arm, steering knuckle, steering tie rod, and wheels. Each spherical hinge provides 3 constraint equations, each rotary hinge provides 4 constraint equations, and each movable hinge provides 5 constraint equations. The steering mechanism model is mainly composed of steering tie rod, steering rocker arm, empty rocker arm, steering wheel, steering drive shaft, and so on. It adopts an inclined arm type rear suspension model, which is mainly composed of a left inclined arm and a right inclined arm.

ADAMS/View provides five types of tire models: Delft tire model, Fiala tire model, Smithers tire model, UA tire model, and User Defined tire model. Among them, the Fiala tire model, UA tire model, and User Defined tire model are analytical models, and the Delft tire model and Smithers tire model are test models. UA tire is the most used tire model, and the paper uses the UA tire model.

Because the input of the vehicle ride comfort analysis is a random road roughness input, a random road surface should be appropriately constructed as the input of the virtual prototype model established above. The generation of random roads must not only conform to a certain random distribution law but also meet the requirements of tires. Random roads must meet the tire requirements: firstly, the position of the road should be below the tire; secondly, the upward direction of the road should point to the side where the tire is located; thirdly, the size of the road should be determined according to the needs of simulation.

In ADAMS, an uneven road is a three-dimensional surface composed of a series of triangular plane elements. The triangular element is composed of a series of nodes. The $x$ and $y$ coordinates of these nodes must meet certain rules, and the $z$ coordinate only represents the width of the road. These nodes form a pavement unit according to a certain rule. And then, the static and dynamic friction coefficient in the pavement unit is set to simulate the real road surface. 
A complete vehicle model is established by connecting each subsystem model established above according to the corresponding constraints shown in Figure 19.

The built vehicle model and the random road surface generated by the road generation software are selected. And the simulation time and step length are set in the ADAMS software for simulation so that the vehicle can drive at a constant speed of $60 \mathrm{~km} / \mathrm{h}$. When the vehicle is simulated for a period of time on random roads of grades $\mathrm{A}, \mathrm{B}, \mathrm{D}$, and $\mathrm{E}$, the measured vertical acceleration and elevation acceleration of the body are set as the neural network training samples.

The vertical acceleration and elevation angular acceleration of the body obtained by ADAMS/View on the C-level road, as shown in Figures 20 and 21, are chosen, respectively, and substituted into the trained network for calculation. The identification value and virtual test value are shown in Figure 22. The relative error of identification is shown in Figure 23. It can be seen that the identification value is not much different from the ADAMS/View virtual test value, which verifies the effectiveness and correctness of using the NARX neural network to identify road roughness.

\section{Conclusion}

A 7-DOF ride comfort model is established, and the NARX neural network and its training process and structure design are studied and summarized. The input and output of the NARX neural network are obtained through simulation. The correlation coefficient and root mean square error are used as the evaluation indicators of the identification effect of the NARX neural network. The results show that the obtained neural network has an $R$ of $95.690 \%$ and an RMSE of 0.0085 at a common speed of $60 \mathrm{~km} / \mathrm{h}$ on B-level road and an $R$ of $92.380 \%$ and an RMSE of 0.0268 at a common speed of $60 \mathrm{~km} / \mathrm{h}$ on C-level road, which has ideal identification accuracy. And also the maximum value of the relative error of the identified B-level and C-level road surface is $0.22 \%$ and $0.41 \%$. The maximum value of the relative error of the identified B-level and C-level road surface after adding noise is $3.7 \%$ and $4.65 \%$. Therefore, using the method to identify road roughness has a small relative error and strong antinoise ability. The identified road roughness will have an important reference value for in-depth analysis of the dynamic response of the highway pavement structure.

The research in this paper is currently limited to the overall level of the road without considering the impact of the road slope. In fact, road slope recognition is also a very important aspect of vehicle dynamics research. Combining road slope recognition and slope road surface unevenness recognition will become a direction for future research. In addition, how to establish real road test verification is also another direction for future research. The advancement of these two directions requires more comprehensive research and analysis of road roughness recognition methods based on neural networks in theory and methods.

\section{Data Availability}

The related data used to support the findings of this study are available from the corresponding author upon request.

\section{Conflicts of Interest}

The authors declare that they have no conflicts of interest.

\section{Acknowledgments}

This work was supported by the Science and Technology Program Foundation of Weifang under Grant 2015GX007. The first author gratefully acknowledges the support agency.

\section{References}

[1] P. Guo and J.-H. Zhang, "Numerical model and multi-objective optimization analysis of vehicle vibration," Journal of Zhejiang University-Science A, vol. 18, no. 5, pp. 393-412, 2017.

[2] K. V. Gangadharan and S. Chandramohan, "Analytical studies on ride quality and ride comfort in chennai mass rapid transit system (MRTS) railroad vehicle," Journal of The Institution of Engineers (India): Series C, vol. 99, no. 6, pp. 737-742, 2018.

[3] I. Youn, M. A. Khan, N. Uddin, E. Youn, and M. Tomizuka, "Road disturbance estimation for the optimal preview control of an active suspension systems based on tracked vehicle model," International Journal of Automotive Technology, vol. 18, no. 2, pp. 307-316, 2017.

[4] K. Hemanth, H. Kumar, and K. V. Gangadharan, "Vertical dynamic analysis of a quarter car suspension system with MR damper," Journal of the Brazilian Society of Mechanical Sciences and Engineering, vol. 39, no. 1, pp. 41-51, 2017.

[5] Y. Qin, J. Guan, L. Gu, Y. Li, and R. Liu, "Pavement recognition technology based on adaptive neural fuzzy network," Journal of Beijing Institute of Technology, vol. 35, no. 5, pp. 481-489, 2015.

[6] L. Gabrielli, L. Ambrosini, and F. Vesperini, "Processing acoustic data with siamese neural networks for enhanced road roughness classification," in Proceedings of the International Joint Conference on Neural Networks, pp. 1-7, Budapest, Hungary, July 2019.

[7] Q. Liu, L. Sun, A. Kornhauser, J. Sun, and N. Sangwa, "Road roughness acquisition and classification using improved restricted Boltzmann machine deep learning algorithm," Sensor Review, vol. 39, no. 6, pp. 733-742, 2019.

[8] P. Liu, B. Liu, T. Dong, and C. Zhang, "Road roughness identification and shift control study for a heavy-duty powertrain,” Energy Procedia, vol. 105, pp. 2885-2890, 2017.

[9] X. Liu, H. Wang, Y. Shan, and T. He, "Construction of road roughness in left and right wheel paths based on PSD and coherence function," Mechanical Systems and Signal Processing, vol. 60-61, pp. 668-677, 2015.

[10] C. Gorges, K. Öztürk, and R. Liebich, "Impact detection using a machine learning approach and experimental road roughness classification," Mechanical Systems and Signal Processing, vol. 117, pp. 738-756, 2019. 
[11] P. Múčka, G. J. Stein, and P. Tobolka, "Whole-body vibration and vertical road profile displacement power spectral density," Vehicle System Dynamics, vol. 58, no. 4, pp. 1-28, 2020.

[12] G. Mastinu, A. Lattuada, and G. Matrascia, "Straight-ahead running of road vehicles-analytical formulae including full tyre characteristics," Vehicle System Dynamics, vol. 57, no. 12, pp. 1-31, 2019.

[13] Y. Ma, J. Zhao, H. Zhao, C. Lu, and H. Chen, "MPC-based slip ratio control for electric vehicle considering road roughness," IEEE Access, vol. 7, pp. 52405-52413, 2019.

[14] P. Múčka, "Vibration dose value in passenger car and road roughness," Journal of Transportation Engineering, Part B: Pavements, vol. 146, no. 4, pp. 1-15, 2020.

[15] S.-W. Kang, J.-S. Kim, and G.-W. Kim, "Road roughness estimation based on discrete Kalman filter with unknown input," Vehicle System Dynamics, vol. 57, no. 10, pp. 1-15, 2018.

[16] B. A. Kansake and S. Frimpong, "Analytical modelling of dump truck tire dynamic response to haul road surface excitations," International Journal of Mining, Reclamation And Environment, vol. 34, no. 1, pp. 1-18, 2020.

[17] G.-W. Kim, S.-W. Kang, J.-S. Kim, and J.-S. Oh, "Simultaneous estimation of state and unknown road roughness input for vehicle suspension control system based on discrete Kalman filter," Proceedings of the Institution of Mechanical Engineers, Part D: Journal of Automobile Engineering, vol. 234, no. 6, pp. 1610-1622, 2020.

[18] H. A. Hamersma and P. S. Els, "Vehicle suspension force and road profile prediction on undulating roads," Vehicle System Dynamics, vol. 59, pp. 1-28, 2020.

[19] Y. Liu and D. Cui, "Collaborative model analysis on ride comfort and handling stability," Journal of Vibroengineering, vol. 21, no. 6, pp. 1724-1737, 2019.

[20] J. Jiang, M. Seaid, M. S. Mohamed, and H. Li, "Inverse algorithm for real-time road roughness estimation for autonomous vehicles," Archive of Applied Mechanics, vol. 90, no. 6, pp. 1333-1348, 2020.

[21] S. Godbole, N. Lam, and M. Mafas Mohamed Muhinadeen, "Vehicle-road interaction analysis for pounding between cargo and trailer-bed," Vehicle System Dynamics, vol. 59, pp. 1-22, 2019.

[22] J. Li, W. C. Guo, Q. Zhao, and S. F. Gu, "Road roughness identification based on vehicle responses," Journal of Jilin University (Engineering and Technology Edition), vol. 49, no. 6, pp. 1810-1817, 2019.

[23] C. Lin and Y. Shi, "Road roughness recognition based on NARX neural network," Journal of Nanjing University of Science and Technology, vol. 44, no. 3, pp. 298-304, 2020. 